\title{
Synergistic Effect of Micro-Nano-Hybrid Surfaces and Sr Doping on the Osteogenic and Angiogenic Capacity of Hydroxyapatite Bioceramics Scaffolds
}

\author{
Shengjie Jiang $\mathbb{D}^{1}$, Xiuhui Wang ${ }^{2}$, Yuhan $\mathrm{Ma}^{3}$, Yuning Zhou ${ }^{4}$, Lu Liu ${ }^{5}$, Fei Yu ${ }^{5}$, Bing Fang ${ }^{5}$, Kaili Lin ', \\ Lunguo $\mathrm{Xia}^{5}$, Ming Cai \\ 'Department of Oral \& Cranio-Maxillofacial Surgery, Shanghai Ninth People's Hospital, College of Stomatology, Shanghai Jiao Tong University School \\ of Medicine, National Clinical Research Center for Oral Diseases, Shanghai Key Laboratory of Stomatology \& Shanghai Research Institute of \\ Stomatology, Shanghai, People's Republic of China; 'Institute of Translational Medicine, Shanghai University, Shanghai, People's Republic of China; \\ ${ }^{3}$ Department of Stomatology, Medical college of Soochow University, Jiangsu, People's Republic of China; ${ }^{4}$ Department of Oral Surgery, Shanghai \\ Ninth People's Hospital, College of Stomatology, Shanghai Jiao Tong University School of Medicine, National Clinical Research Center for Oral \\ Diseases, Shanghai Key Laboratory of Stomatology \& Shanghai Research Institute of Stomatology, Shanghai, People's Republic of China; ${ }^{5}$ Department \\ of Orthodontics, Shanghai Ninth People's Hospital, Shanghai Jiao Tong University School of Medicine, Shanghai, People's Republic of China
}

Correspondence: Lunguo Xia, Department of Orthodontics, Shanghai Ninth People's Hospital, Shanghai Jiao Tong University School of Medicine, No.639, Zhizaoju Road, Huangpu District, Shanghai, People's Republic of China, Tel +86 I376I955I06, Fax +86-2 I-63 I36856, Email xialunguo@hotmail.com; Ming Cai, Department of Oral \& Cranio-Maxillofacial Surgery, Shanghai Ninth People’s Hospital, College of Stomatology, Shanghai Jiao Tong University School of Medicine, No. 639, Zhizaoju Road, Huangpu District, Shanghai, People’s Republic of China, Tel +86 I39I8490900, Fax +86-2I-63 I36856, Email zidanecm500@I26.com

Background: The synergistic effect of chemical element doping and surface modification is considered a novel way to regulate cell biological responses and improve the osteoinductive ability of biomaterials.

Methods: Hydroxyapatite (HAp) bioceramics with micro-nano-hybrid (a mixture of microrods and nanorods) surfaces and different strontium (Sr) doping contents of 2.5, 5, 10, and 20\% ( $\mathrm{Sr}_{\mathrm{x}}-\mathrm{mnHAp}, \mathrm{x}: 2.5,5,10$ and 20\%) were prepared via a hydrothermal transformation method. The effect of $\mathrm{Sr}_{\mathrm{x}}$-mnHAp on osteogenesis and angiogenesis of bone marrow stromal cells (BMSCs) was evaluated in vitro, and the bioceramics scaffolds were further implanted into rat calvarial defects for the observation of bone regeneration in vivo.

Results: HAp bioceramics with micro-nano-hybrid surfaces (mnHAp) could facilitate cell spreading, proliferation ability, ALP activity, and gene expression of osteogenic and angiogenic factors, including COL1, BSP, BMP-2, OPN, VEGF, and ANG-1. More importantly, $\mathrm{Sr}_{\mathrm{x}}$-mnHAp (x: 2.5, 5, 10 and 20\%) further promoted cellular osteogenic activity, and $\mathrm{Sr}_{10}$-mnHAp possessed the best stimulatory effect. The results of calvarial defects revealed that $\mathrm{Sr}_{10}$-mnHAp could promote more bone and blood vessel regeneration, with mnHAp and HAp bioceramics (dense and flat surfaces) as compared.

Conclusion: The present study suggests that HAp bioceramics with micro-nano-hybrid surface and Sr doping had synergistic promotion effects on bone regeneration, which can be a promising material for bone defect repair.

Keywords: bioceramics, scaffolds, surface modification, element doping, bone regeneration

\section{Introduction}

Bone transplantation is a crucial method to reconstruct bone defects caused by trauma, tumors, and other diseases, and autologous bone grafts remain the "gold standard" for bone transplantation. However, the limitation of insufficient bone mass and related postoperative complications have facilitated the development of substitute materials. ${ }^{1,2}$ Bioceramic materials are widely used as a physiological scaffold for bone defect repair because of its excellent biocompatibility and bioactivity, and are currently considered as the most promising alternative to autologous bone grafting. The porous structure of bioceramics facilitates the adhesion of osteoblasts, transport of nutrients, and speeds up the process of bone resorption and reconstruction, ${ }^{3}$ which makes it better for repairing large bone defects. ${ }^{4}$ you hereby accept the Terms. Non-commercial uses of the work are permitted without any further permission from Dove Medical Press Limited, provided the work is properly attributed. For permission for commercial use of this work, please see paragraphs 4.2 and 5 of our Terms (https://www.dovepress.com/terms.php). 
The inorganic minerals in human bone tissue have a multilevel ordered structure and contain many microelements. From the viewpoint of bio mimics, we can tune the osteoinduction ability of materials by controlling the surface microstructure and element doping. The ideal scaffold materials for bone regeneration require an appropriate threedimensional microporous structure for cell growth and nutrient metabolism. ${ }^{2,5}$ For bioceramics scaffolds, the pores are $150 \sim 500 \mu \mathrm{m}$ in diameter and over $50 \%$ in porosity are appropriate to stimulate cell response, and nanostructured surfaces and high connectivity between pores is also important. ${ }^{1,6-8}$ The results of our recent study confirmed that the HAp bioceramics with nanostructured modified topography significantly enhanced cell viability, spreading, and osteogenic differentiation of BMSCs and bone formation, mineralization and vascularization in vivo. ${ }^{9}$ Moreover, suitable surface chemistry plays critical roles in cell viability, spreading, proliferation, and osteogenic differentiation. $^{2,5}$ Biomaterials can be modified by the introduction of functional inorganic ions. Recently, more attention has been given to strontium $(\mathrm{Sr})$, which is an important trace element in the human body, and $99 \%$ of $\mathrm{Sr}$ exists in bones. Sr can improve the mechanical properties and modify the bone balance toward osteosynthesis. ${ }^{10}$ Recent studies ${ }^{11}$ have found that $\mathrm{Sr}$ can enhance the proliferation of osteoblasts during bone metabolism. Yang et al ${ }^{12}$ suggested that the surface of Sr-doped hydroxyapatite can significantly increase the growth of osteoblasts. The results of Wang et $\mathrm{a}^{13}$ confirmed that the Sr-HAp coatings significantly promoted osteoblast attachment and proliferation as the Sr content increased. Recently, researchers focused on the preparation of strontium-substituted bioceramics and their application in bone regeneration. ${ }^{14-16}$ However, few studies have focused on the synergistic promotion of nanostructures and $\mathrm{Sr}$ doping on bone regeneration.

Therefore, based on the above research and our previous results, ${ }^{9,17}$ we proposed that the combination of nanostructure surfaces and Sr-doping might lead to synergistic enhancement of osteogenesis and angiogenesis. ${ }^{18,19}$ Herein, HAp bioceramics with micro-nano-hybrid surfaces and different strontium $(\mathrm{Sr})$ doping contents of 2.5, 5, 10, and 20\% ( $\mathrm{Sr}_{\mathrm{x}}$-mnHAp, $\mathrm{x}: 2.5,5,10$ and 20\%) were fabricated via the hydrothermal transformation method. The effect on cell adhesion, proliferation, and ALP activity and the expression of genes involved in osteogenesis and angiogenesis were investigated to determine the optimal Sr doping content, followed by calvarial defect experiments to evaluate bone regeneration and vascularization in vivo.

\section{Materials and Methods}

\section{Preparation of Micro-Nano-Hybrid HAp (mnHAp) and Sr-Doped mnHAp $\left(\mathrm{Sr}_{\mathrm{x}}\right.$-mnHAp) Bioceramics}

The micro-nano-hybrid HAp (mnHAp) and $\mathrm{Sr}$-doped mnHAp ( $\mathrm{Sr}_{\mathrm{x}}$-mnHAp, x: 2.5, 5, 10 and 20\%) bioceramics were prepared by the hydrothermal transformation method. First, a-tricalcium phosphate (a-TCP) and Sr-doped a-TCP with different doping contents of 2.5, 5, 10, and 20\% ( $\mathrm{Sr}_{\mathrm{x}}$-a-TCP, $\mathrm{x}: 2.5,5,10$ and 20\%) powders were synthesized by chemical precipitation. ${ }^{20}$ Then, the synthesized a-TCP and $\mathrm{Sr}_{\mathrm{x}}$-a-TCP powders were mixed with $7 \mathrm{wt} \%$ polyvinyl alcohol (PVA), drypressed into discs $10 \mathrm{~mm}$ in diameter and $2 \mathrm{~mm}$ in thickness under a pressure of $5 \mathrm{MPa}$, and further calcined at $1050{ }^{\circ} \mathrm{C}$ for 5 $\mathrm{h}$ to obtain a-TCP and $\mathrm{Sr}_{\mathrm{x}}$-a-TCP bioceramics, respectively. ${ }^{21}$ Finally, the mnHAp and $\mathrm{Sr}_{\mathrm{x}}$-mnHAp bioceramics were prepared using a-TCP and Sr-a-TCP discs as precursors via hydrothermal reaction in $\mathrm{pH}=7$ aqueous solution at $180{ }^{\circ} \mathrm{C}$ for 72 h. ${ }^{17,20}$ In addition, HAp bioceramics with dense and flat surfaces were used as controls and labeled S0. ${ }^{9}$

\section{Samples Characterization}

HAp (S0), mnHAp (S3), and $\mathrm{Sr}_{\mathrm{x}}$-mnHAp (x: 2.5, 5, 10 and 20\%) were incubated in $1 \mathrm{~mL}$ of $\alpha$-Minimum Essential Medium (a-MEM, Gibco, USA) for 1 and $4 \mathrm{~d}$, respectively. The medium of each sample changed daily and the concentrations of $\mathrm{Sr}$, $\mathrm{Ca}$, and $\mathrm{P}$ ions released from $\mathrm{HAp}, \mathrm{mnHAp}$, and $\mathrm{Sr}_{\mathrm{x}}-\mathrm{mnHAp}_{\mathrm{A}}$ at each timepoint were evaluated using inductively coupled plasma-atomic emission spectrometry (ICP-AES). The crystal phase compositions of the samples were determined with XRD (Rigaku, Japan), and the surface microstructures were observed by SEM (JEOL, Japan). ${ }^{17}$ 


\section{Cell Extraction and Culture}

Bone marrow stem cells (BMSCs) were harvested as previously described. ${ }^{17}$ Briefly, Sprague-Dawley (SD) rats (4 weeks old) were selected and injected intraperitoneally with an overdose of pentobarbital sodium. The scalp was separated for exposure, and both femora were cut off. Fresh marrow was flushed out and cultured in a-MEM (Gibco, USA) containing 10\% FBS (Gibco, USA) and 1\% penicillin and streptomycin (Hyclone, USA). The culture medium was maintained at $37{ }^{\circ} \mathrm{C}$ in a $5 \% \mathrm{CO}_{2}$ incubator and renewed 3 times a week. The cells were passaged after reaching $90 \%$ confluence, and passages 2-4 were used in the following experiment. All animal experiments and procedures received approval from the Animal Ethics Committee of the Shanghai Ninth People's Hospital Affiliated to Shanghai Jiaotong University, School of Medicine and conducted in compliance with the guidelines of Institutional Animal Care and Use Committee of Shanghai Ninth People's Hospital Affiliated to Shanghai JiaoTong University, School of Medicine [SYXK (Hu) 2016-0016].

\section{Cell Morphology and Adhesion}

Phalloidin staining was performed to evaluate the morphology and spreading of the BMSCs seeded onto samples S0, S3, 2.5Sr, $5 \mathrm{Sr}, 10 \mathrm{Sr}$, and $20 \mathrm{Sr}$ at an initial density of $1 \times 10^{4}$ cells per $\mathrm{mL}$ in 24 -well plates. At $6 \mathrm{~h}$ after seeding, all specimens were fixed with $4 \%$ formaldehyde for $10 \mathrm{~min}$, and then treated with 1\% Triton X-100 for $5 \mathrm{~min}$. Next, these specimens were incubated with phalloidin (Sigma, USA) for $30 \mathrm{~min}$, followed by DAPI (Sigma, USA) for approximately 30s. Finally, actin cytoskeletons were observed by fluorescence microscopy (Leica, Germany).

\section{Cell Proliferation}

The proliferation of BMSCs in the samples was investigated by MTT assay, with a cell density of $1 \times 10^{4}$ cells per $\mathrm{mL}$ in 24-well plates. After culturing for 1, 4, and $7 \mathrm{~d}$, the culture medium was replaced, and the BMSC-seeded bioceramics were rinsed and incubated with sterile MTT (Amresco, USA) at $37^{\circ} \mathrm{C}$ for $4 \mathrm{~h}$. DMSO solution (Sigma, USA) was then added and incubated for $10 \mathrm{~min}$ to dissolve formazan. The OD value was read at $490 \mathrm{~nm}$ by a microplate Reader (Biotek, USA). All experiments were repeated 3 times.

\section{ALP Staining and Activity}

BMSCs were cultured onto $\mathrm{S} 0, \mathrm{~S} 3,2.5 \mathrm{Sr}, 5 \mathrm{Sr}, 10 \mathrm{Sr}$, and $20 \mathrm{Sr}$ samples at a cell density of $1 \times 10^{4}$ cells per mL in 24 -well plates. After culturing for $10 \mathrm{~d}$, ALP staining was performed with a BCIP/NBT Alkaline Phosphatase Color Development Kit (Beyotime, China). The ALP activity was then assessed at 4, 7, and $10 \mathrm{~d}^{22}$ Briefly, all samples were lysed in $1 \%$ Triton X-100 for $30 \mathrm{~min}$ at $4{ }^{\circ} \mathrm{C}$, and the cellular lysate of each well was collected and centrifuged at $4{ }^{\circ} \mathrm{C}(12,000 \mathrm{rpm} \times$

Table I Primer Sequences of the Selected Genes

\begin{tabular}{|c|c|c|c|}
\hline Target Gene & Primers (F = Forward; $\mathbf{R}=$ Reverse) & Accession Number & Product Size (bp) \\
\hline COLI & $\begin{array}{l}\text { F:5'CTGCCCAGAAGAATATGTATCACC3' } \\
\text { R:5'GAAGCAAAGTTTCCTCCAAGACC3' }\end{array}$ & NM_053304.I & 198 \\
\hline BSP & $\begin{array}{l}\text { F: 5'AGAAAGAGCAGCACGGTTGAGT3' } \\
\text { R: 5'GACCCTCGTAGCCTTCATAGCC3' }\end{array}$ & NM_0I2587.2 & 175 \\
\hline BMP-2 & $\begin{array}{l}\text { F: 5'TGGGTTTGTGGTGGAAGTGGC3' } \\
\text { R: 5'TGGATGTCCTTTACCGTCGTG3' }\end{array}$ & NM_017I78.2 & 154 \\
\hline OPN & $\begin{array}{l}\text { F: 5'CCAAGCGTGGAAACACACAGCC3' } \\
\text { R: 5'GGCTTTGGAACTCGCCTGACTG3' }\end{array}$ & NM_0I288I.2 & 165 \\
\hline VEGF & $\begin{array}{l}\text { F: 5'GGCTCTGAAACCATGAACTTTCT3' } \\
\text { R: 5'GCAGTAGCTGCGCTGGTAGAC3' }\end{array}$ & NM_00III 0334.2 & 165 \\
\hline ANG-I & $\begin{array}{l}\text { F:5'GGACAGCAGGCAAACAGAGCAGC3' } \\
\text { R: 5'CCACAGGCATCAAACCACCAACC } 3^{\prime}\end{array}$ & NM_053546.2 & 130 \\
\hline GAPDH & $\begin{array}{l}\text { F: 5'CCTGCACCACCAACTGCTTA3' } \\
\text { R: 5'GGCCATCCACAGTCTTCTGAG3' }\end{array}$ & NM_0I7008.4 & 120 \\
\hline
\end{tabular}


$10 \mathrm{~min}$ ). Then, the OD value was determined at $520 \mathrm{~nm}$ with a microplate Reader (Bio-Tek, USA), and total cellular protein was determined by a BCA protein kit (Beyotime, China) at $562 \mathrm{~nm}$. Finally, ALP activity was evaluated by normalizing to total protein content. All experiments were repeated 3 times.

\section{Quantitative Real-Time PCR (qRT-PCR) and Western Blot Experiment}

qRT-PCR was carried out to assess the expression of osteogenic and angiogenic factors in BMSCs cultured in samples S0, S3, 2.5Sr, 5Sr, $10 \mathrm{Sr}$, and $20 \mathrm{Sr}$. After culturing for 4 and $7 \mathrm{~d}$, total RNA of the samples was isolated according to our previous study. ${ }^{21}$ Briefly, the cells cultured in the bioceramics were lysed in TRIzol Reagent (Life Technologies, USA) and reverse transcribed to cDNA by PrimeScript ${ }^{\mathrm{TM}}$ RT reagent Kit (TaKaRa, Japan). The expression levels of osteogenesis- and angiogenesis-related genes were further evaluated by qRT-PCR analysis, including COL1, BSP, BMP-2, OPN, VEGF, and ANG-1. GAPDH was selected as a housekeeping gene to normalize the expression level. The primer sequences selected are listed in Table 1. All experiments were repeated 3 times.

Western blot experiment was applied to assess expression of BMP-2. BMSCs were cultured in samples S0, S3, 2.5Sr, $5 \mathrm{Sr}, 10 \mathrm{Sr}$, and $20 \mathrm{Sr}$ for $7 \mathrm{~d}$. Total protein was extracted and centrifuged at 12,000 rpm for 15 minutes. Then, the samples were separated via sodium dodecyl sulfate polyacrylamide gel electrophoresis (SDS-PAGE) at 80 volts for 20 minutes and 120 volts for 50 minutes, and transferred to polyvinylidene fluoride membranes (PVDF, Millipore, USA). The PVDF membranes were incubated with primary antibody (Abcam, UK) at $37{ }^{\circ} \mathrm{C}$ for $2 \mathrm{~h}$. After that, the membranes were incubated with HRP-conjugated secondary antibody (Abcam, UK) for $1 \mathrm{~h}$ at room temperature. The protein bands were visualized, and the images were captured by an automated luminescent image analysis system (Tanon, China).

\section{Animal Experiment}

Calvarial defects were established in twelve 6-week-old SD rats as previously described. ${ }^{17}$ Animal experiments and procedures received approval from the Animal Ethics Committee of the Shanghai Ninth People's Hospital Affiliated to

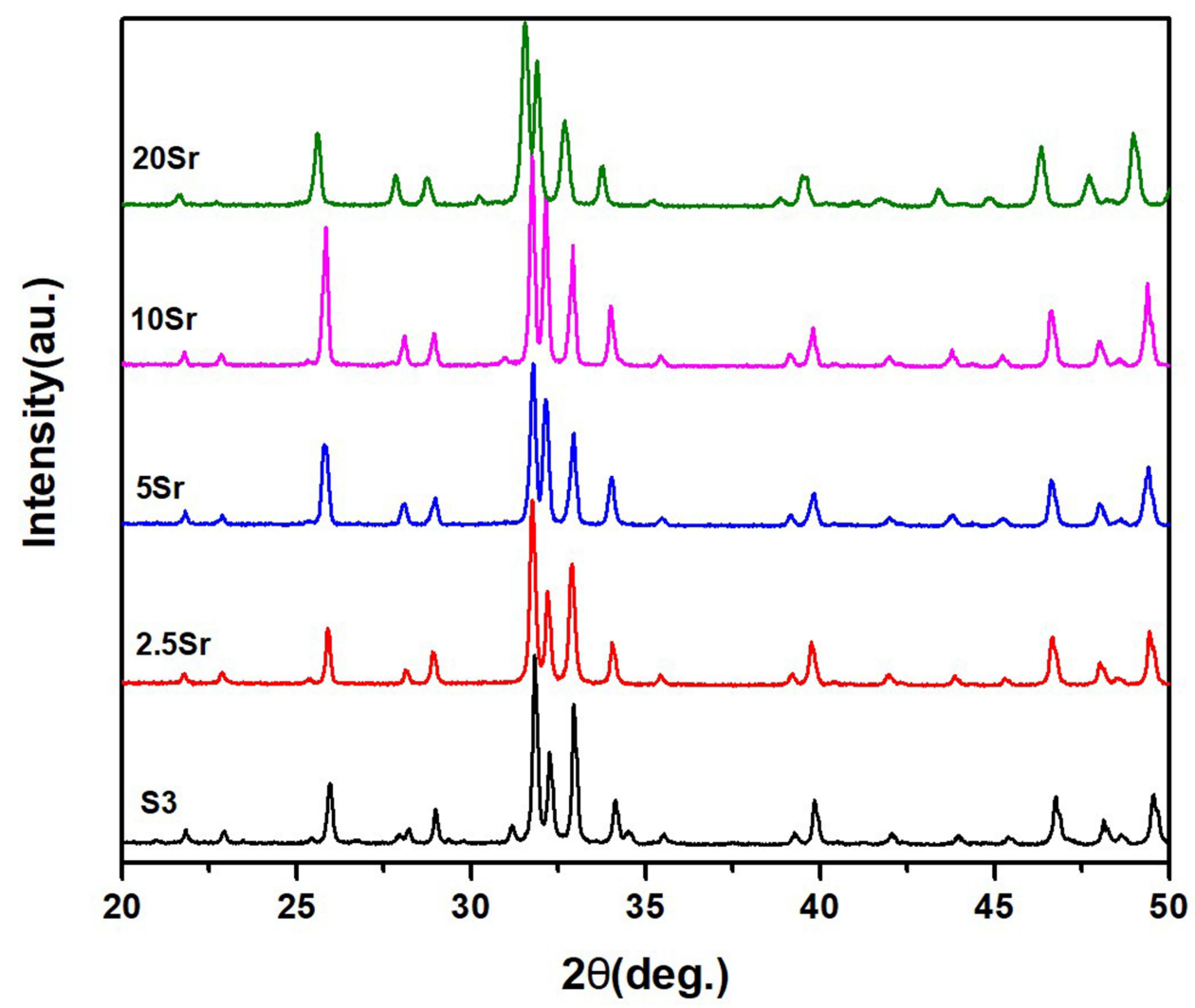

Figure I XRD results of mnHAp (S3) and $\mathrm{Sr}_{\mathrm{x}}$-mnHAp bioceramics $(2.5 \mathrm{Sr}, 5 \mathrm{Sr}, 10 \mathrm{Sr}, 20 \mathrm{Sr})$. 

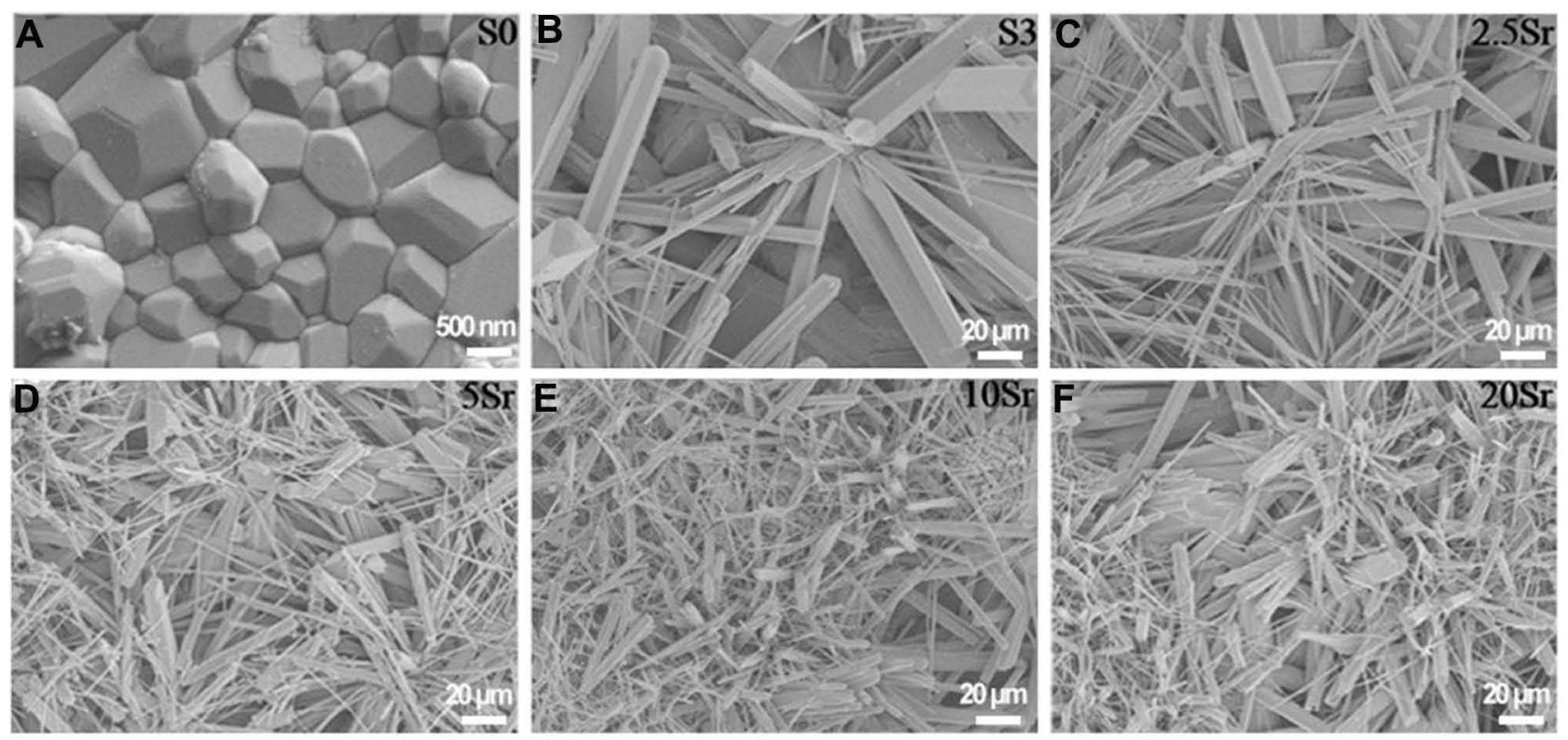

Figure 2 SEM micrographs of topographic surface for HAp (A), mnHAp (B), and $\mathrm{Sr}_{\mathbf{x}}-\mathrm{mnHAp}(\mathbf{C}-\mathbf{F})$ : $(\mathbf{A}) \mathrm{scale}$ bar=500 $\mathrm{nm},(\mathbf{B}-\mathbf{F})$ scale bar=20 $\mu \mathrm{m}$.

Shanghai Jiaotong University, School of Medicine. All rats were randomly divided into the following 3 groups: S0, S3, and $10 \mathrm{Sr}$ ( $\mathrm{n}=4$ for each group). Briefly, all rats were injected intraperitoneally with pentobarbital $(3.5 \mathrm{mg} / 100 \mathrm{~g})$. Under sterile conditions, a $2 \mathrm{~cm}$ longitudinal incision was made, and two symmetrical round defects $(5 \mathrm{~mm}$ in diameter) were created using the implant drill at each rat. Subsequently, the HAp, mnHAp, and $\mathrm{Sr}_{10}$-mnHAp were placed into the defects, and the operation incision was carefully sutured with absorbable sutures.

\section{Micro-CT Analyses}

At the 8th week after implantation, all rats were sacrificed and perfused with Microfil (Flowtech, USA) to observe new blood vessels. ${ }^{23}$ The samples were decalcified using EDTA for 1 month and then scanned by microcomputed tomography (Scanco, Switzerland), the percentages of new blood vessels were quantitatively determined with Image-Pro 5.0 (Media Cybernetic, USA). For the observation of new bone, the specimens were fixed in $4 \%$ paraformaldehyde for $2 \mathrm{~d}$ and then transferred to $75 \%$ alcohol. Finally, the samples were scanned by microcomputed tomography. Bone volume fraction $(\mathrm{BV} / \mathrm{TV})$ and trabecular thickness $(\mathrm{Tb} . \mathrm{Th})$ were calculated with auxiliary software (Scanco, Switzerland). ${ }^{24}$
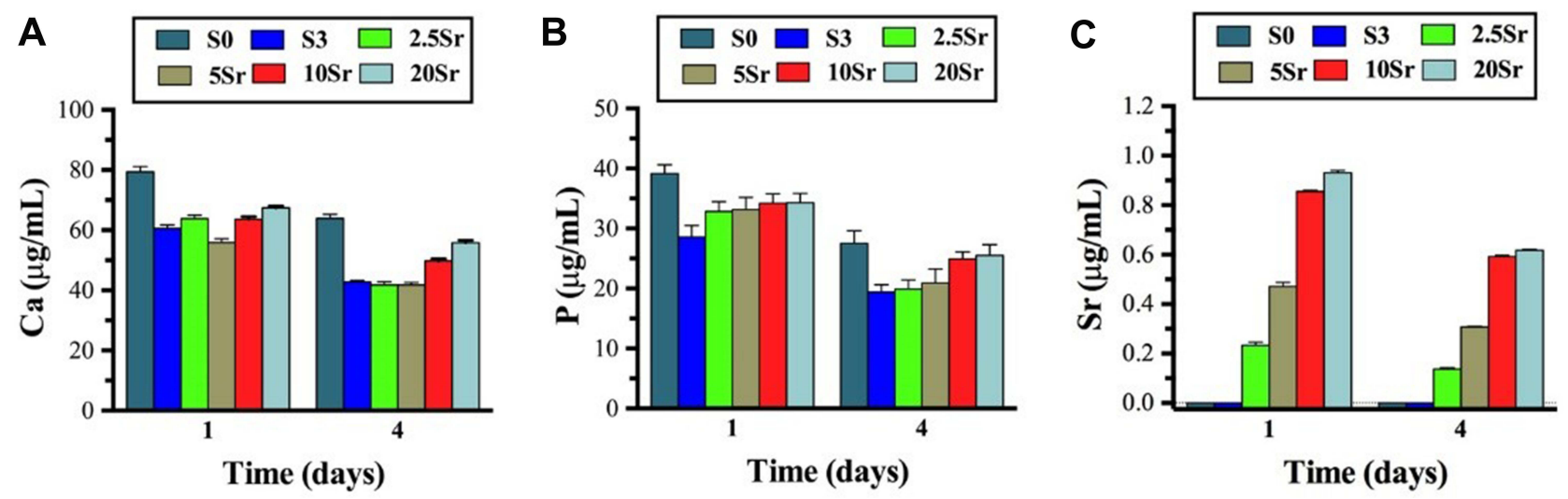

Figure 3 The release of $\mathrm{Ca}(\mathbf{A}), \mathrm{P}(\mathbf{B})$, and $\mathrm{Sr}(\mathbf{C})$ ions at $\mathrm{I}$ and $4 \mathrm{~d}$. 

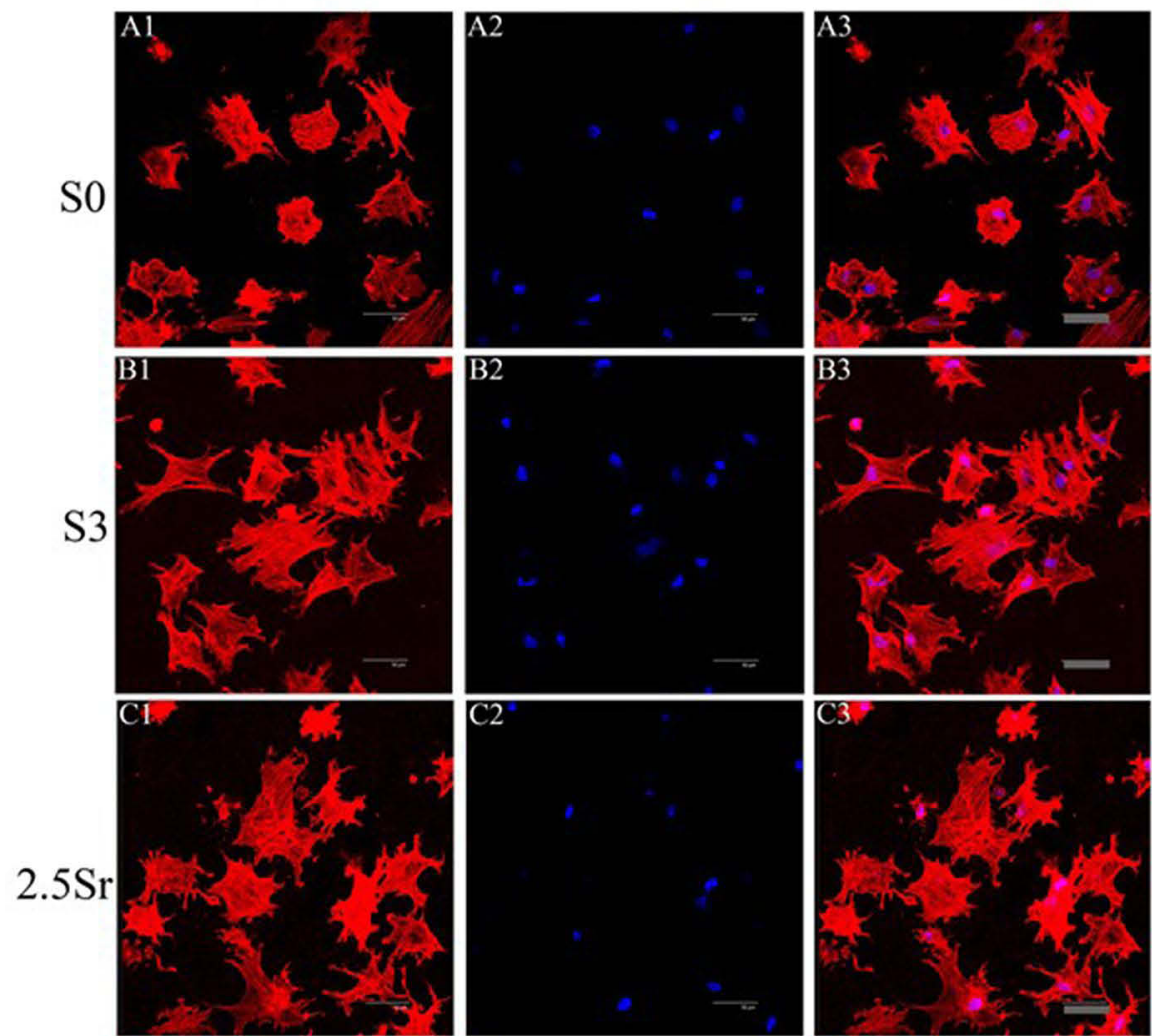

C2
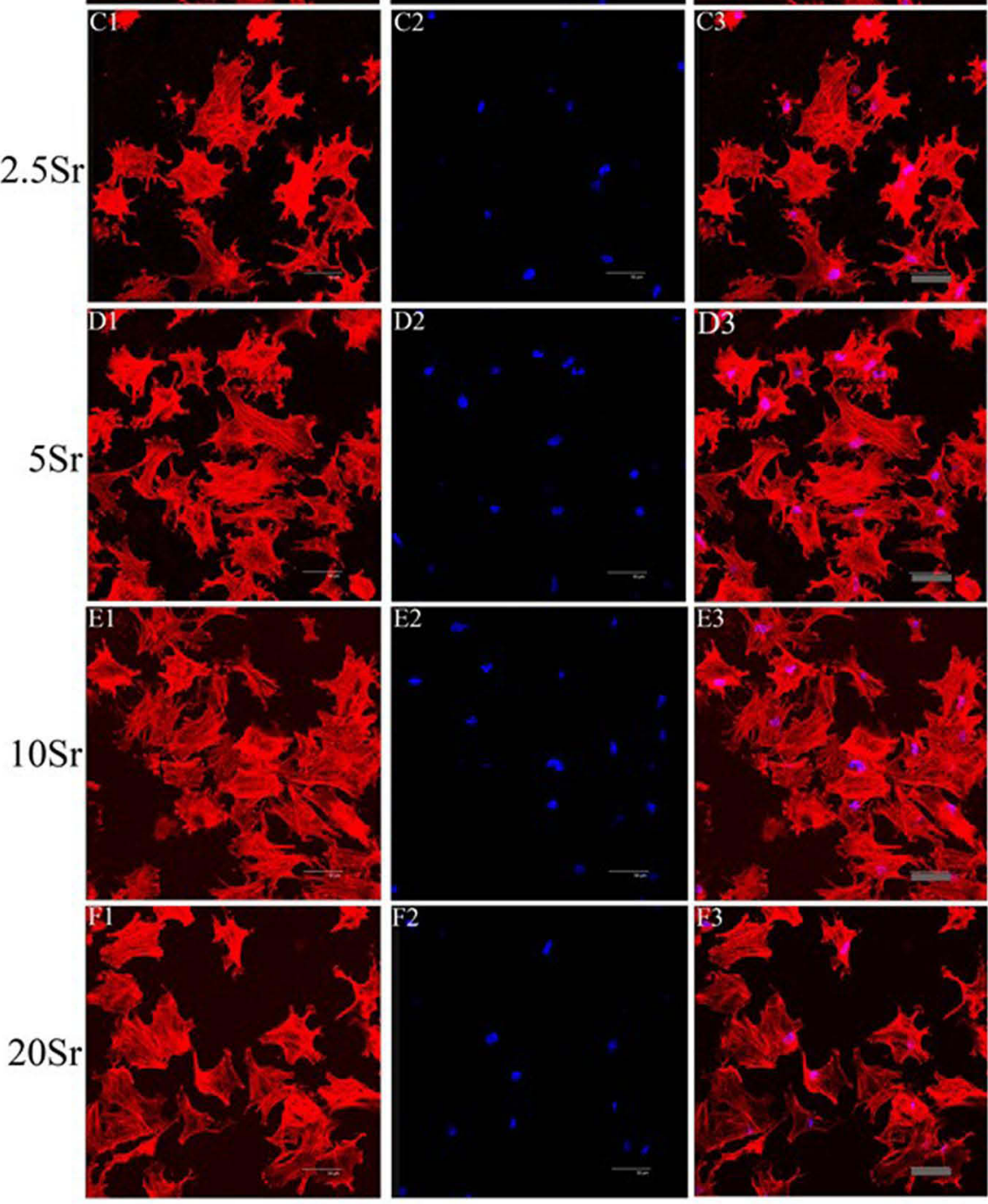

Figure 4 Fluorescence microscopy images of the cells in samples $\mathrm{SO}, \mathrm{S3}, 2.5 \mathrm{Sr}, 5 \mathrm{Sr}$, IOSr, and $20 \mathrm{Sr}$ after 6 h: red represents the actin cytoskeleton (AI-FI), blue represents the nucleus (A2-F2), and the merged images of the actin cytoskeleton and the nucleus (A3-F3): scale bar=50 $\mu \mathrm{m}$. 


\section{Histological Analyses}

All specimens were decalcified with 10\% EDTA, dehydrated in increased concentrations of ethanol (75\% to $100 \%)$ and embedded in PMMA for 3 weeks. Tissue blocks were sectioned by a microtome (Leica, Germany) and further ground to approximately $40 \mu \mathrm{m}$. Next, the sections were subjected to Van Gieson staining for histological analysis, and the proportion of bone regeneration in the defect area was quantitatively determined with Image-Pro 5.0 (Media Cybernetic, USA). ${ }^{17,25}$

\section{Statistical Analyses}

All data are expressed as the means \pm standard deviation (SD), and statistical analysis was performed using SPSS 17.0 software (SPSS Inc., USA). A $p$ value $<0.05$ was considered statistically significant.

\section{Results}

\section{Characterization of the Samples}

XRD results of mnHAp and $\mathrm{Sr}_{\mathrm{x}}$-mnHAp (x: 2.5, 5, 10 and 20\%) are shown in Figure 1. All the diffraction peaks confirmed that these samples were converted into HAp without any other phases after the hydrothermal transformation method. The obvious micro-nanorods topography surfaces of mnHAp (Figure 2B) and $\mathrm{Sr}_{\mathrm{x}}$-mnHAp (Figure 2C-F) could be observed by SEM, and $\mathrm{Sr}_{10}$-mnHAp possessed the densest rod-shaped structure (Figure 2E). The lengths of the microrods and nanorods were approximately 10 20 $\mu \mathrm{m}$, while the diameters were approximately $1 \sim 4 \mu \mathrm{m}$ and 80 120 $\mathrm{nm}$, respectively. As a comparison, a dense and flat surface with a particle size of approximately $0.9 \mu \mathrm{m}$ was observed on control sample S0 (Figure 2A).

The results of ICP-AES analysis revealed that the release of $\mathrm{Sr}$ ions could be detected in $\mathrm{Sr}_{\mathrm{x}}$-mnHAp bioceramics and showed an ascending trend with increasing $\mathrm{Sr}$ content at each timepoint (Figure 3C). No significant differences in the release amount of $\mathrm{Ca}$ and $\mathrm{P}$ could be found among HAp, mnHAp, and $\mathrm{Sr}_{\mathrm{x}}-\mathrm{mnHAp}$ (Figure $3 \mathrm{~A}$ and $\mathrm{B}$ ).

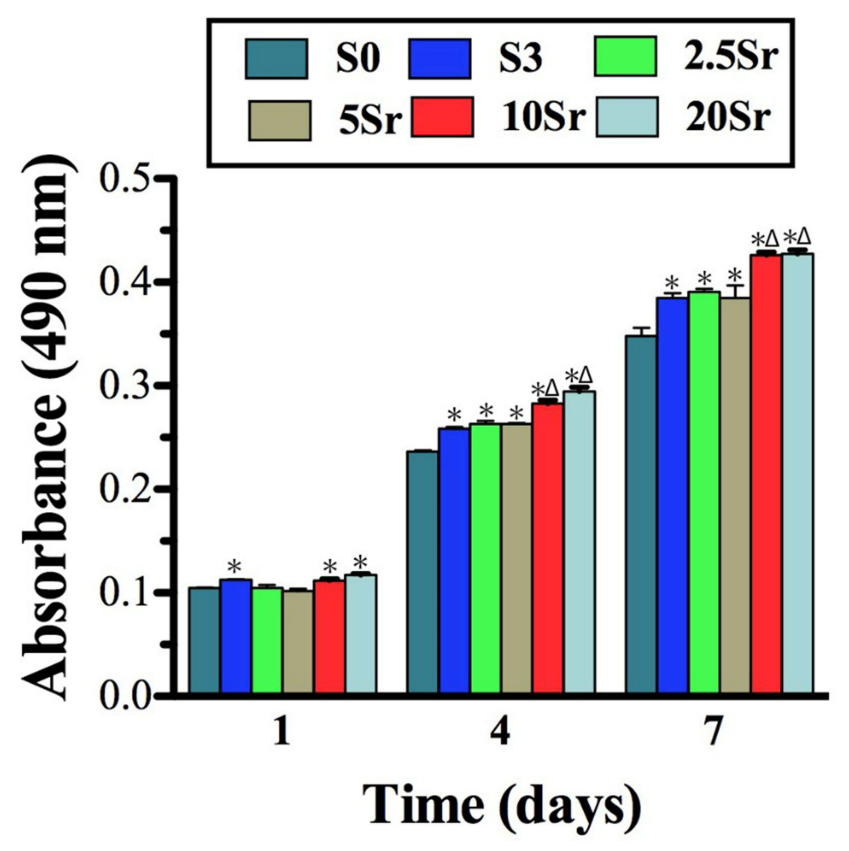

Figure $5 \mathrm{MTT}$ analysis of the cells seeded in samples $\mathrm{SO}, \mathrm{S3}, 2.5 \mathrm{Sr}, 5 \mathrm{Sr}, 10 \mathrm{Sr}$ and $20 \mathrm{Sr}$. ${ }^{*}$ indicates a significant difference with $\mathrm{SO}, \Delta$ indicates a significant difference with $\mathrm{S} 3$, $\mathrm{p}<0.05)$. 


\section{The Morphology of BMSCs}

As shown in Figure 4, the actin cytoskeleton was stained red, and the nucleus was stained blue. After being cultured for $6 \mathrm{~h}$, fluorescence microscopy images showed that the cells seeded in sample S0 spread slightly and almost had a round shape (Figure 4A1). Meanwhile, as a comparison, the cells seeded on the mnHAp (S3, 2.5Sr, 5Sr, 10Sr, and 20Sr) exhibited better early cell attachment and demonstrated a typical polygonal morphology with apparent stretch tentacles. No significant differences in the cell morphology and quantity could be found with increasing $\mathrm{Sr}$ content. This experiment showed that the nanostructure surface could promote the early cell attachment of BMSCs instead of the concentrations of Sr ions.

\section{Cell Proliferation}

The cells adhered to the HAp, mnHAp and $\mathrm{Sr}_{\mathrm{x}}$-mnHAp bioceramics proliferated through the MTT assay (Figure 5). The cells cultured on mnHAp (S3, 2.5Sr, $5 \mathrm{Sr}, 10 \mathrm{Sr}$, and 20Sr) displayed higher proliferation than control samples on days 4 and 7. $(\mathrm{p}<0.05)$ In addition, among the $\mathrm{Sr}_{\mathrm{x}}$-mnHAp with different $\mathrm{Sr}$ contents, proliferation significantly proceeded on $\mathrm{Sr}_{10}$-mnHAp and $\mathrm{Sr}_{20}$-mnHAp on days 4 and $7(\mathrm{p}<0.05)$.
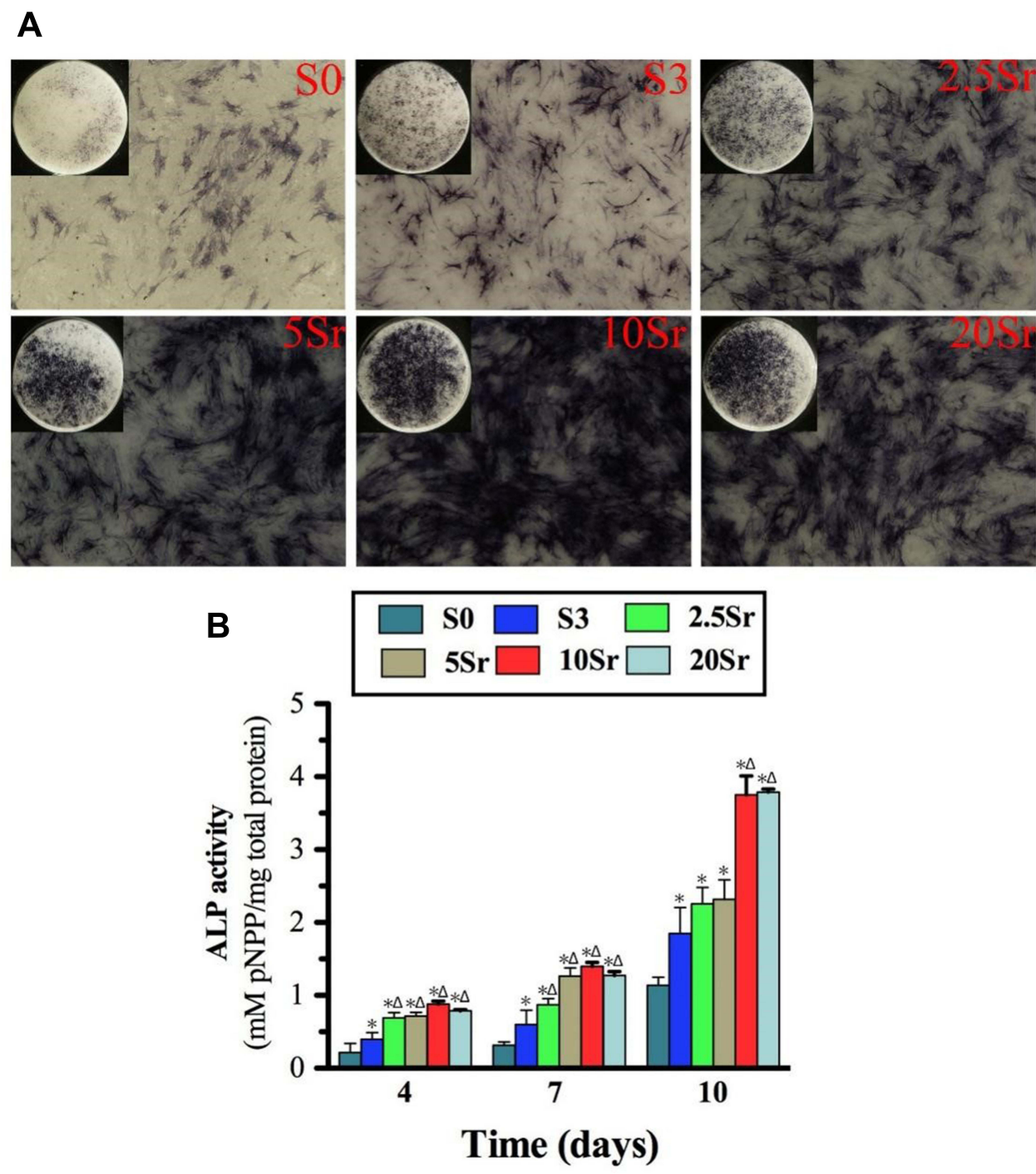

Figure 6 ALP activity measurement: (A) ALP staining of BMSCs seeded onto samples S0, S3, 2.5Sr, $5 \mathrm{Sr}$, IOSr, and $20 \mathrm{Sr}$ at $10 \mathrm{~d}$. (B) ALP quantitative analysis of cells seeded in samples S0, S3, 2.5Sr, 5Sr, $10 \mathrm{Sr}$ and $20 \mathrm{Sr}$ for 4,7 and $10 \mathrm{~d}$. (*indicates a significant difference with S0, $\Delta$ indicates a significant difference with S3, $\mathrm{P}<0.05$ ). 


\section{ALP Activity Assay}

The cells cultured on mnHAp bioceramics possessed more intensive ALP staining, with control samples (dense and flat surface) compared (Figure 6A). Moreover, the staining became deeper with $\mathrm{Sr}$ doping (2.5Sr, $5 \mathrm{Sr}, 10 \mathrm{Sr}$, and $20 \mathrm{Sr}$ ). In particular, the deepest staining was found on the $\mathrm{Sr}_{10}$-mnHAp sample. The ALP semi-quantification assay on days 4,7 and 10 further confirmed the staining results (Figure 6B). The ALP activity increased throughout the whole assay period, and the mnHAp bioceramics possessed higher cellular ALP activity. More importantly, the samples with $\mathrm{Sr}$ doping achieved better ALP activity on days 4 and $7(\mathrm{p}<0.05)$. When the experiment time was extended to $10 \mathrm{~d}$, compared to mnHAp, only $\mathrm{Sr}_{10}$-mnHAp and $\mathrm{Sr}_{20}$-mnHAp further enhanced ALP activity.

\section{qRT-PCR Assay and Western Blot Experiment}

qRT-PCR was carried out to analyze the expression of osteogenesis and angiogenesis factors in the cells cultured on HAp, mnHAp and $\mathrm{Sr}_{\mathrm{x}}$-mnHAp at days 4 and 7. As shown in Figure 7, the mnHAp bioceramics (S3, 2.5 Sr, $5 \mathrm{Sr}, 10 \mathrm{Sr}$, and

\section{A}
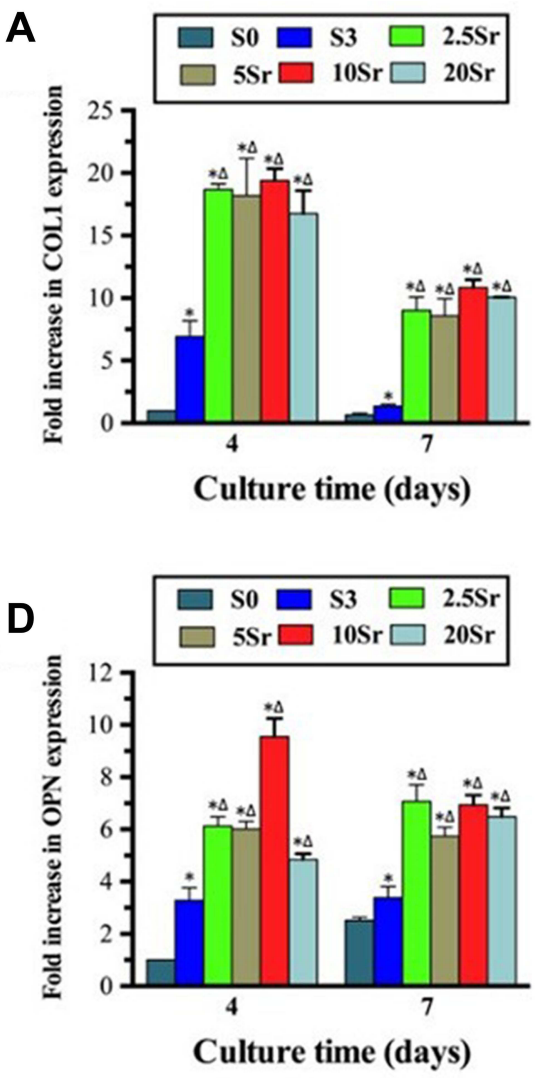

B
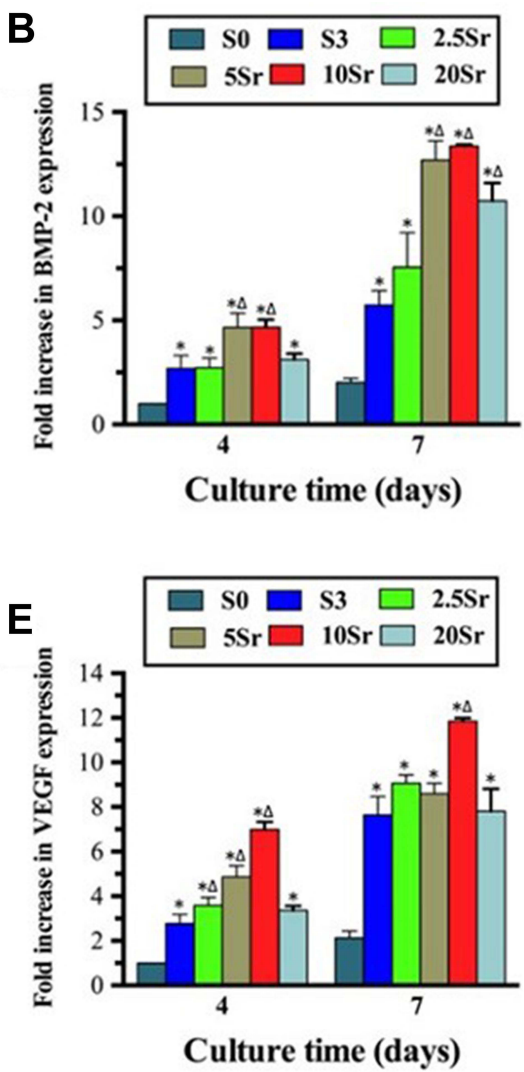
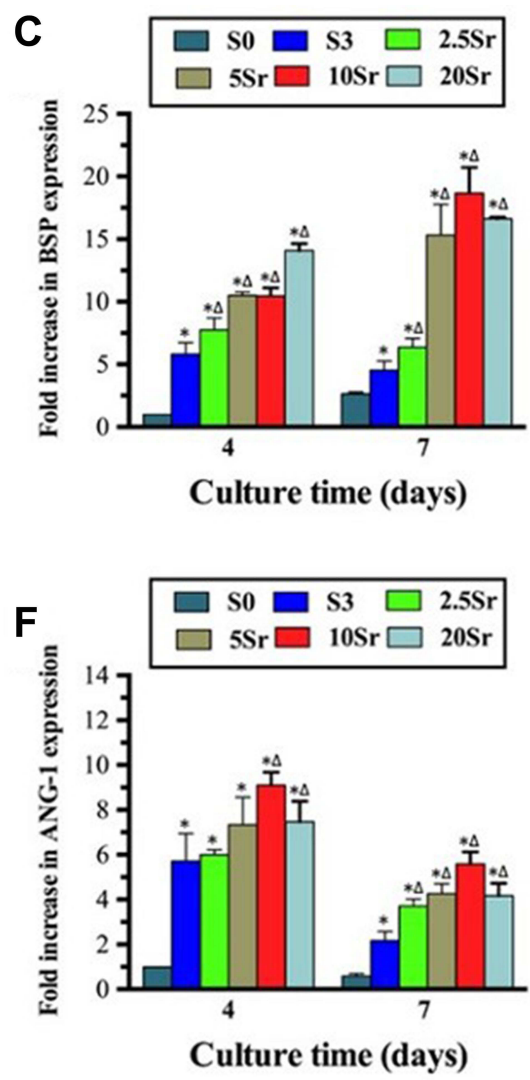

$\mathbf{G}$

BMP-2

\section{$2.5 \mathrm{Sr} 5 \mathrm{Sr} 10 \mathrm{Sr} 20 \mathrm{Sr}$ S3 So}

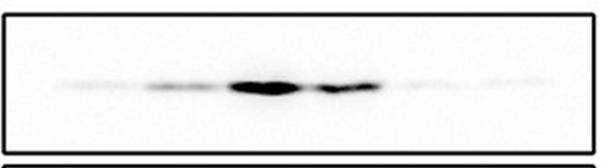

Bactin

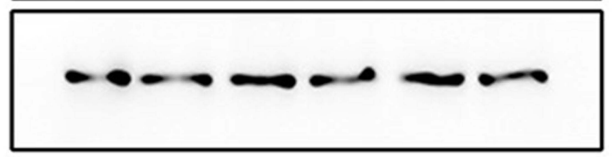

Figure 7 qRT-PCR analysis of the expression of COLI (A), BMP-2 (B), BSP (C), OPN (D), VEGF (E), and ANG-I (F) and Western blot result of BMP-2 (G). (*indicates a significant difference with $\mathrm{S} 0, \Delta$ indicates a significant difference with $\mathrm{S} 3, \mathrm{p}<0.05)$. 
20Sr) could strengthen the expression of COL1, BSP, BMP-2, OPN, VEGF and ANG-1 with sample S0 (dense and flat surface) compared at 4 and $7 \mathrm{~d}$. Furthermore, Sr doping improved the mRNA levels of COL1, BSP, and OPN at 4 and 7 $\mathrm{d}$ and ANG-1 at $7 \mathrm{~d}$. The western bolt result of day 7 confirmed the enhanced expression of BMP-2 in the $\mathrm{Sr}_{\mathrm{x}}-\mathrm{mnHAp}$, especially in the $\mathrm{Sr}_{10}$-mnHAp. More importantly, the promotion effect of $\mathrm{Sr}$ doping occurred in a dose-dependent manner, and $\mathrm{Sr}_{10}$-mnHAp achieved the best stimulation ability.

\section{Micro-CT Measurement}

Micro-CT scanning and analysis were performed to assess the bone regeneration of the calvarial defect areas. From Figure 8A, we can see that more bone formation in the surface and pores of the mnHAp bioceramics at the $8^{\text {th }}$ week after implantation $(\mathrm{p}<0.05)$ and $\mathrm{Sr}_{10}$-mnHAp achieved the best repair effect with $\mathrm{S} 0$ and $\mathrm{S} 3$ compared $(\mathrm{p}<0.05)$. Morphometric analysis further proved that the BV/TV ratio (Figure 8B) and $\mathrm{Tb}$. Th (Figure 8C) in mnHAp bioceramics were higher than that of pure HAp. Moreover, significant differences were found between mnHAp and $\mathrm{Sr}_{10}$-mnHAp $(\mathrm{p}<0.05)$. Figure 9 showed the angiographic results, more blood vessels were found in the implant site of the mnHAp bioceramics $(\mathrm{p}<0.05)$, and the $\mathrm{Sr}_{10}$-mnHAp groups possessed the most newly formed blood vessels. The results of quantitative analysis also confirmed that samples $\mathrm{S} 3$ and $10 \mathrm{Sr}$ possessed more blood vessels, and the differences between samples $10 \mathrm{Sr}$ and $\mathrm{S} 3$ were remarkable $(\mathrm{p}<0.05)$.
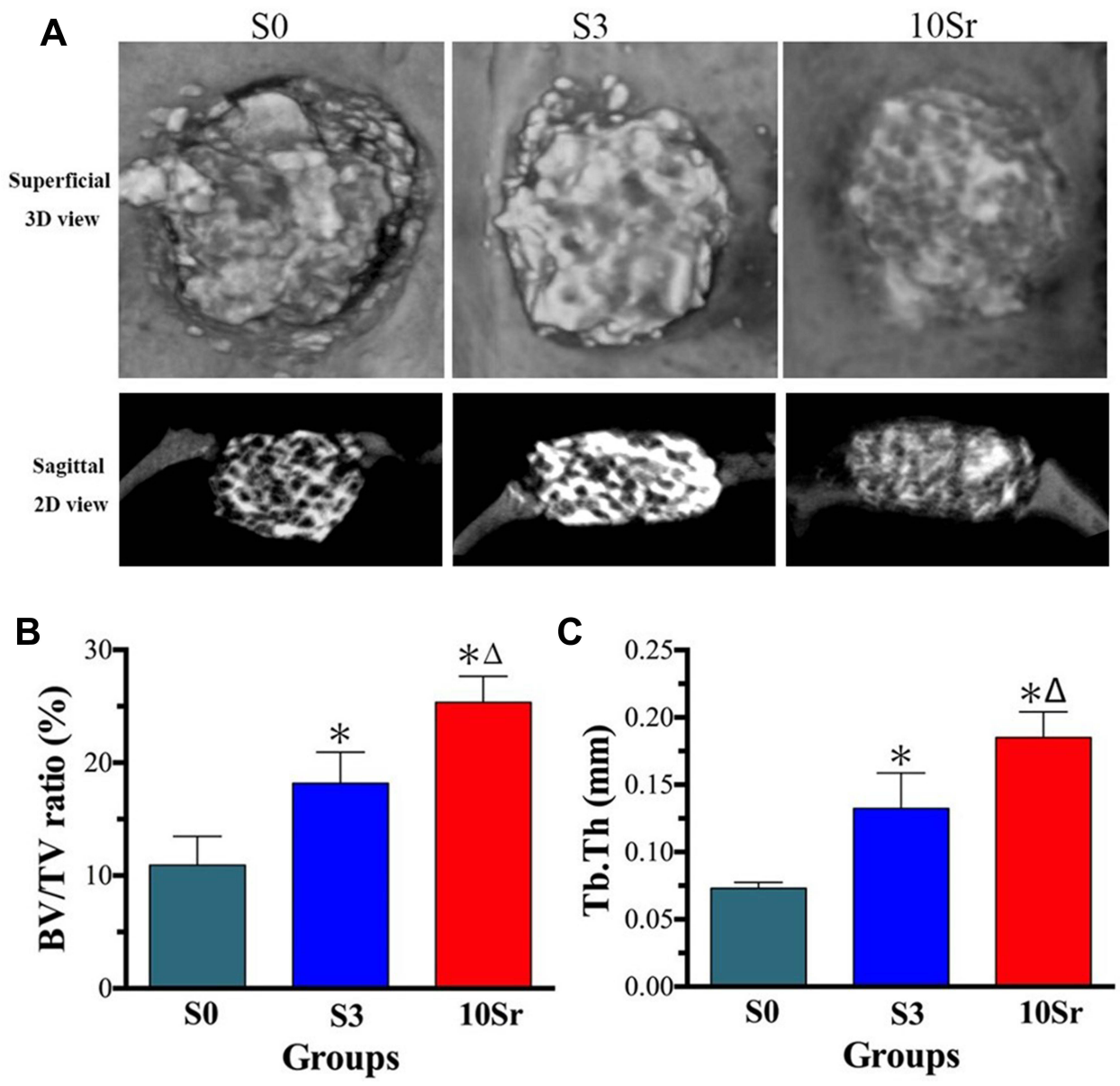

Figure 8 Micro-CT assessment at 8 weeks after implantation. (A) 3D and 2D images of newly formed bone of groups S0, S3, and I0Sr. Quantitative measurement of the BV/ TV ratio $(\mathbf{B})$ and $\mathrm{Tb}$. Th $(\mathbf{C})$. (*indicates a significant difference with S0, $\Delta$ indicates a significant difference with $\mathrm{S} 3, \mathrm{p}<0.05)$. 

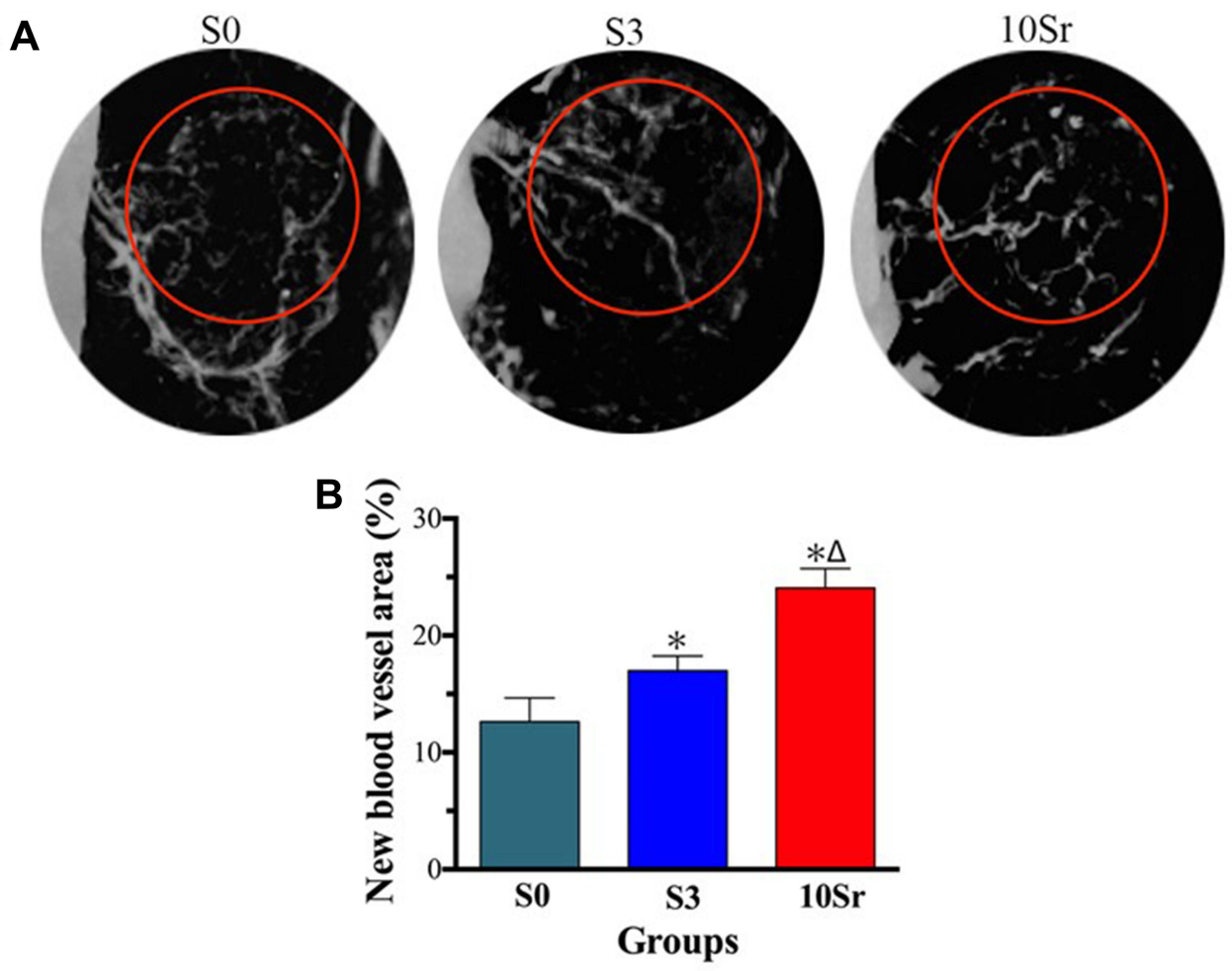

Figure 9 Micro-CT angiography at the 8th week after implantation. (A) Images of new blood vessels in groups S0, S3, and I0Sr. (B) Quantitative measurement of the new blood vessel area. (*indicates a significant difference with S0, $\Delta$ indicates a significant difference with S3, $\mathrm{p}<0.05$ ).

\section{Histological and Histomorphometric Analysis}

Van Gieson staining was applied to observe bone regeneration in the surface and pores of the HAp bioceramics. As shown in Figure 10A, bone formation was only found on the edge of the defect in group S0, while groups S3 and 10Sr achieved more new bone formation from the margins to the Center, especially group 10Sr. As shown in Figure 10B, the results of bone histomorphometric analysis further confirmed that groups $\mathrm{S} 3$ and 10Sr possessed more newly formed bone areas. More importantly, remarkable differences could be found between groups S3 and 10Sr, which indicates that $\mathrm{Sr}_{10}$-mnHAp has the best effect on promoting bone formation ( $\left.\mathrm{p}<0.05\right)$.

\section{Discussion}

The skeleton is an integral part of the human body and has a limited capacity to regenerate after large bone defects caused by acute injuries, fall fractures, or tumors. The repair of bone defects and bone regeneration remain challenging problems in clinical treatment. ${ }^{2}$ Currently, reconstruction of these skeletal defects is often achieved by autogenous and allogeneic bone transplantation, although they have drawbacks separately. The emergence and development of tissue engineering offers tremendous potential. HAp ceramics are a multifunctional biological material with good biocompatibility and bioactivity but are limited in Clinical application because of their insufficient osteoinduction ability. ${ }^{4}$ Osteoblast/material interactions play a fundamental role in the biological response of host cells and can be modified by the surface characteristics of bone grafts. ${ }^{26}$

Numerous studies have shown that controlling the surface morphology and roughness of materials is a direct and effective strategy to improve biological properties, and surface topography can affect cell attachment and subsequent proliferation and differentiation. ${ }^{9,27-29}$ Our previous study demonstrated that the microstructure surface can support cell adhesion, which is critical for osteogenic proliferation and differentiation. ${ }^{9}$ Changing the chemical compositions of the surface by element doping can also improve the osteogenic properties of biomaterials. ${ }^{21}$ Trace elementSr has been applied to the preparation of bone tissue engineering scaffolds, which can promote bone regeneration and inhibit bone resorption. ${ }^{30}$ Previous studies showed that appropriate release of Sr ions could activate osteogenesis-related signal transduction pathways, 
A

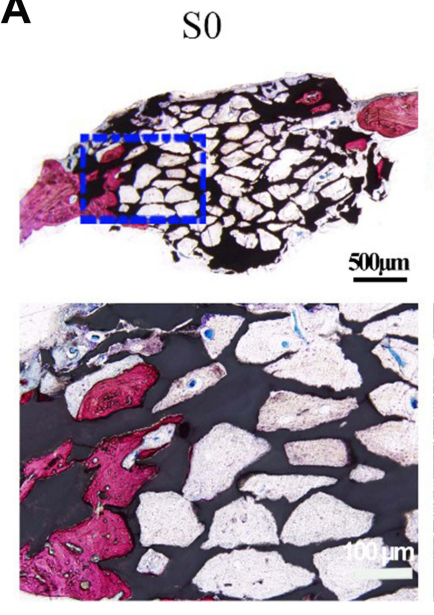

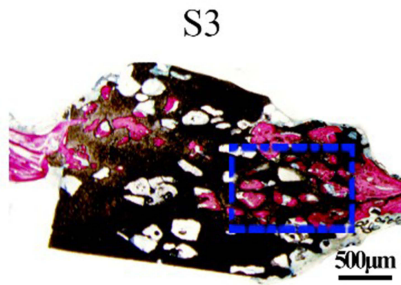
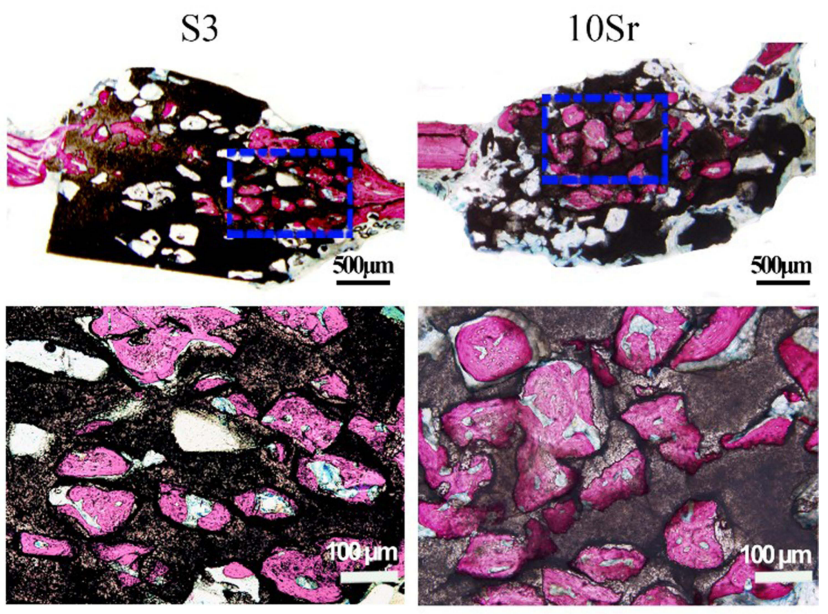

B

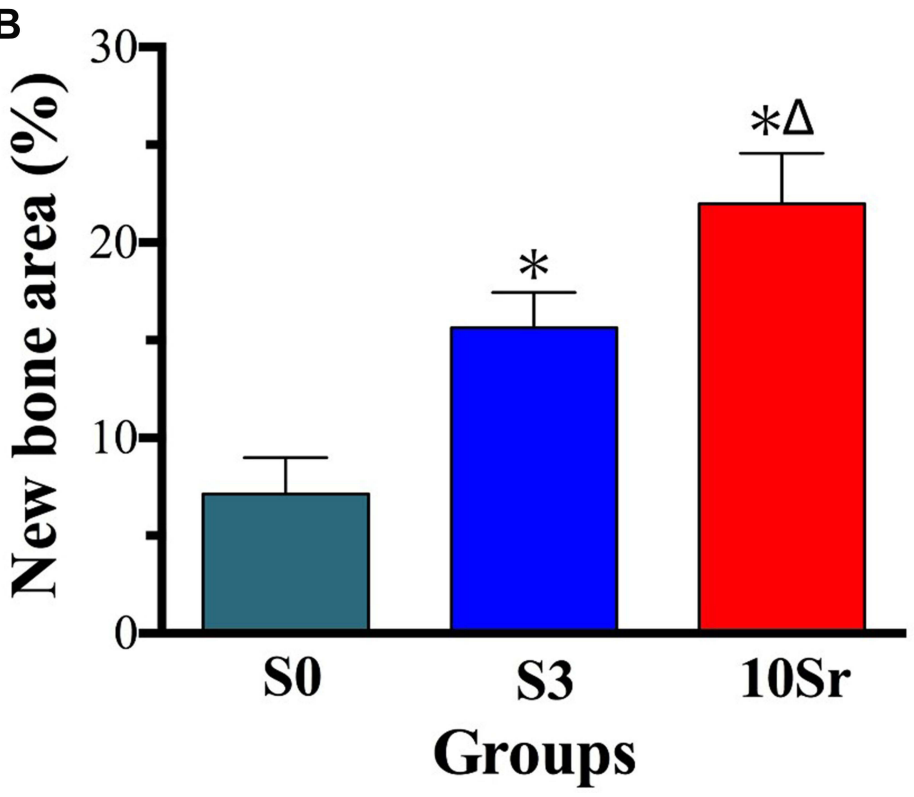

Figure 10 Histological and histomorphometric analysis: (A) Images of Van Gieson's staining of bone formation at the 8th week after implantation. (B) Quantitative measurement of the new bone area. (*indicates a significant difference with S0, $\Delta$ indicates a significant difference with $\mathrm{S} 3, \mathrm{p}<0.05$ ).

stimulate osteogenesis gene expression and ultimately new bone formation in a dose-dependent manner. ${ }^{31,32}$ Most of the previous studies mainly focused on the effects and underlying mechanisms of surface modification or chemical composition changes on the biological characteristics. Whether osteogenic differentiation and angiogenesis could be promoted by topographic modification and element doping is still lacking and requires further evaluation.

Herein, HAp bioceramics with micro-nano-hybrid surfaces and different $\mathrm{Sr}$ doping contents $\left(\mathrm{Sr}_{\mathrm{x}}\right.$-mnHAp, x: 2.5, 5, 10 and $20 \%$ ) were synthesized using $\mathrm{Sr}_{\mathrm{x}}-\alpha-\mathrm{TCP}$ as a precursor via hydrothermal transformation. ${ }^{20}$ The XRD patterns confirmed that all the samples were completely transformed into HAp, and the visible micro-nanorods structure on the surface of mnHAp and $\mathrm{Sr}_{\mathrm{x}}-\mathrm{mnHAp}$ could be observed by SEM. According to the ICP-AES analysis, the release of $\mathrm{Sr}$

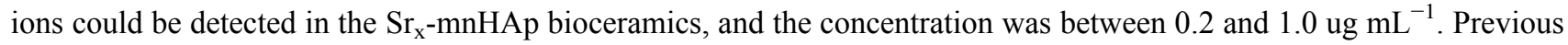
Research suggested that the suitable concentration of $\mathrm{Sr}$ ions varies from 0.2107 to $21.07 \mu \mathrm{g} \mathrm{mL}^{-1}$, which indicated that the release of $\mathrm{Sr}$ is in an appropriate range. ${ }^{33}$

Subsequently, the effects of mnHAp and $\mathrm{Sr}_{\mathrm{x}}$-mnHAp bioceramics on BMSCs were evaluated in vitro. Previous studies have suggested that the physical properties of biomaterial scaffolds can affect adhesion, migration, and 
differentiation into osteoblasts. ${ }^{34-37}$ The cytoskeleton staining assay showed that the cells cultured on the mnHAp exhibited better cell attachment, with typical fibroblastic morphology. However, $\mathrm{Sr}$ doping did not significantly promote cell attachment or extension. It indicates that the nanostructure surface, instead of Sr ions, is the Key promotion factor of cellular responses in the early stages. ALP is considered to be an indicator of osteogenic differentiation and an important index of bone formation and turnover. BMP-2 is the strongest osteoinduction cytokine and can promote bone formation and growth. OCN is tightly related to the maturation of osteoblasts, ${ }^{38}$ and COL1 and BSP are vital genes involved in osteoblastic differentiation. VEGF is the most important factor in angiogenesis, and ANG-1 plays a basic role in promoting maturity and maintaining vascular stabilization. According to the results of MTT, ALP activity, and PCR assays, the mnHAp bioceramics could facilitate proliferation ability, ALP activity and mRNA expression of COL1, BSP, BMP-2, OPN, VEGF, and ANG-1, which is consistent with our previous results. ${ }^{22,39}$ More importantly, Sr doping furthers promoted cellular osteogenic activity, while $\mathrm{Sr}_{10}$-mnHAp possessed the best stimulatory effect. In addition, the results of calvarial defects confirmed that the mnHAp bioceramics could promote bone and blood vessel regeneration with the control samples (dense and flat surface). More importantly, Sr doping further promoted bone and blood vessel regeneration, while $\mathrm{Sr}_{10}$-mnHAp possessed the most stimulatory effect. All the above results proved our hypothesis that micro-nano-hybrid surface and $\mathrm{Sr}$ doping had synergistic promotion effects on bone regeneration, the $\mathrm{Sr}_{\mathrm{x}}-\mathrm{mnHAp}$ bioceramics can be a promising material for bone defect repair. Meanwhile, its multifunctional properties make it a good candidate for potential biomedical applications, including targeted drug delivery applications, and the stable and controlled release of drugs is worthy of further investigation.

\section{Conclusion}

Surface structure and chemical composition are considered to be the key clues to regulate the biological response of biomaterials. Herein, HAp bioceramics with micro-nano-hybrid surface and different $\mathrm{Sr}$ doping contents $\left(\mathrm{Sr}_{\mathrm{x}}-\mathrm{mnHAp}, \mathrm{x}\right.$ : 2.5, 5, 10 and 20\%) were successfully fabricated via a hydrothermal transformation method using $\mathrm{Sr}_{\mathrm{x}}$-a-TCP powder as a precursor without additives. The nanostructure surface can support cell adhesion, and Sr-doping could further enhance osteogenic differentiation with an optimal doping concentration of $10 \%$. Finally, the calvarial defect model showed that the $\mathrm{Sr}_{10}$-mnHAp bioceramics scaffolds possessed better bone regeneration capacity. All of the results confirmed our hypothesis that micro-nano-hybrid surface and $\mathrm{Sr}$ doping have synergistic effects on bone regeneration and provided a new strategy for improving the osteoinduction ability of traditional bioceramics.

\section{Acknowledgments}

This work was sponsored by the National Natural Science Foundation of China (81771115); Natural Science Foundation of Shanghai (20ZR1431000); Science and Technology Commission of Shanghai Municipality (19441906200); Shanghai Rising-Star Program (19QA1405200); CSA Clinical Research Fund (CSA-O2020-04); and Innovative Research Team of High-level Local Universities in Shanghai (SSMU-ZDCX20180902).

\section{Disclosure}

The authors report no conflicts of interest in this work.

\section{References}

1. Nikolova MP, Chavali MS. Recent advances in biomaterials for 3D scaffolds: a review. Bioact Mater. 2019;4(1):271-292. doi:10.1016/j. bioactmat.2019.10.005

2. Turnbull G, Clarke J, Picard F, et al. 3D bioactive composite scaffolds for bone tissue engineering. Bioact Mater. 2018;3(3):278-314. doi:10.1016/j. bioactmat.2017.10.001

3. Nandi SK, Ghosh SK, Kundu B, et al. Evaluation of new porous $\beta$-tri-calcium phosphate ceramic as bone substitute in goat model. Small Rumin Res. 2008;75(2):144-153. doi:10.1016/j.smallrumres.2007.09.006

4. Bohner M, Galea L, Doebelin N. Calcium phosphate bone graft substitutes: failures and hopes. J Eur Ceram Soc. 2012;32(11):2663-2671. doi:10.1016/j.jeurceramsoc.2012.02.028

5. Hutmacher DW. Scaffolds in tissue engineering bone and cartilage. Biomaterials. 2001;21(24):2529-2543. doi:10.1016/S0142-9612(00)00121-6

6. Mastrogiacomo M, Scaglione S, Martinetti R, et al. Role of scaffold internal structure on in vivo bone formation in macroporous calcium phosphate bioceramics. Biomaterials. 2006;27(17):3230-3237. doi:10.1016/j.biomaterials.2006.01.031 
7. Chang BS, Lee CK, Hong KS, et al. Osteoconduction at porous hydroxyapatite with various pore configurations. Biomaterials. 2000;21 (12):1291-1298. doi:10.1016/s0142-9612(00)00030-2

8. Zhang Q, Lu H, Kawazoe N, et al. Pore size effect of collagen scaffolds on cartilage regeneration. Acta Biomater. 2014;10(5):2005-2013. doi:10.1016/j.actbio.2013.12.042

9. Xia L, Lin K, Jiang X, et al. Enhanced osteogenesis through nano-structured surface design of macroporous hydroxyapatite bioceramic scaffolds via activation of ERK and p38 MAPK signaling pathways. J Mater Chem B. 2013;1(40):5403-5416. doi:10.1039/c3tb20945h

10. Braux J, Velard F, Guillaume C, et al. A new insight into the dissociating effect of strontium on bone resorption and formation. Acta Biomater. 2011;7(6):2593-2603. doi:10.1016/j.actbio.2011.02.013

11. Li Y, Shui X, Zhang L, et al. Cancellous bone healing around strontium-doped hydroxyapatite in osteoporotic rats previously treated with zoledronic acid. J Biomed Mater Res Part B. 2016;104(3):476-481. doi:10.1016/j.jeurceramsoc.2012.02.028

12. Yang SP, Lee T-M, Lui T-S. Biological response of Sr-containing coating with various surface treatments on titanium substrate for medical applications. Appl Surf Sci. 2015;346:554-561. doi:10.1016/j.apsusc.2015.03.190

13. Wang W, Zhang Y, Yang J, et al. Effects of Sr-HA with different concentrations of strontium on biological behaviour of osteoblast. Chin J Conserv Dent. 2010;20(02):71-75. doi:10.3724/SP.J.1077.2010.01195

14. Ullah I, Gloria A, Zhang W, et al. Synthesis and characterization of sintered Sr/Fe-modified hydroxyapatite bioceramics for bone tissue engineering applications. ACS Biomater Sci Eng. 2020;6(1):375-388. doi:10.1021/acsbiomaterials.9b01666

15. Zhao R, Chen S, Zhao W, et al. A bioceramic scaffold composed of strontium-doped three-dimensional hydroxyapatite whiskers for enhanced bone regeneration in osteoporotic defects. Theranostics. 2020;10(4):1572-1589. doi:10.7150/thno.40103

16. Kim HW, Kim YJ. Fabrication of strontium-substituted hydroxyapatite scaffolds using 3D printing for enhanced bone regeneration. $J$ Mater Sci. 2021;56(2):1-12. doi:10.1007/s10853-020-05391-y

17. Xia L, Zhang N, Wang X, et al. The synergetic effect of nano-structures and silicon-substitution on the properties of hydroxyapatite scaffolds for bone regeneration. $J$ Mater Chem B. 2016;4(19):3313-3323. doi:10.1039/c6tb00187d

18. Wu X, Tang Z, Wu K, et al. Strontium-calcium phosphate hybrid cement with enhanced osteogenic and angiogenic properties for vascularised bone regeneration. J Mater Chem B. 2021;9(30):5982-5997. doi:10.1039/d1tb00439e

19. Liu L, Yu F, Li L, et al. Bone marrow stromal cells stimulated by strontium-substituted calcium silicate ceramics: release of exosomal miR-146a regulates osteogenesis and angiogenesis. Acta Biomater. 2021;119(1):444-457. doi:10.1016/j.actbio.2020.10.038

20. Lin K, Chang J, Liu X, et al. Synthesis of element-substituted hydroxyapatite with controllable morphology and chemical composition using calcium silicate as precursor. Crystengcomm. 2011;13(15):4850-4855. doi:10.1039/c0ce00835d

21. Zhang X, Li H, Lin C, et al. Synergetic topography and chemistry cues guiding osteogenic differentiation in bone marrow stromal cells through ERK1/2 and p38 MAPK signaling pathway. Biomater Sci. 2018;6(2):418-430. doi:10.1039/c7bm01044c

22. Xia L, Lin K, Jiang X, et al. Effect of nano-structured bioceramic surface on osteogenic differentiation of adipose derived stem cells. Biomaterials. 2014;35(30):8514-8527. doi:10.1016/j.biomaterials.2014.06.028

23. Zou D, Zhang Z, He J, et al. Blood vessel formation in the tissue-engineered bone with the constitutively active form of HIF-1 $\alpha$ mediated BMSCs. Biomaterials. 2012;33(7):2097-2108. doi:10.1016/j.biomaterials.2011.11.053

24. Zhao J, Shen G, Liu C, et al. Enhanced healing of rat calvarial defects with sulfated chitosan-coated calcium-deficient hydroxyapatite/bone morphogenetic protein 2 scaffolds. Tissue Eng Part A. 2012;18(2):185-197. doi:10.1089/ten.TEA.2011.0297

25. Xia L, Yin Z, Mao L, et al. Akermanite bioceramics promote osteogenesis, angiogenesis and suppress osteoclastogenesis for osteoporotic bone regeneration. Sci Rep. 2016;6(1):22005. doi:10.1038/srep22005

26. Anselme K. Osteoblast adhesion on biomaterials. Biomaterials. 2000;21(7):667-681. doi:10.1016/S0142-9612(99)00242-2

27. Colon G, Ward BC, Webster TJ. Increased osteoblast and decreased Staphylococcus epidermidis functions on nanophase $\mathrm{ZnO}$ and TiO2. J Biomed Mater Res A. 2006;78(3):595-604. doi:10.1002/jbm.a.30789

28. Kress S, Neumann A, Weyand B, et al. Stem cell differentiation depending on different surfaces. Adv Biochem Eng Biotechnol. 2011;126:263-283. doi:10.1007/10_2011_108

29. Ramaswamy Y, Roohani I, No YJ, et al. Nature-inspired topographies on hydroxyapatite surfaces regulate stem cells behaviour. Bioact Mater. 2021;6(4):1107-1117. doi:10.1016/j.bioactmat.2020.10.001

30. Bose S, Fielding G, Tarafder S, et al. Understanding of dopant-induced osteogenesis and angiogenesis in calcium phosphate ceramics. Trends Biotechnol. 2013;31(10):594-605. doi:10.1016/j.tibtech.2013.06.005

31. Prasad K, Bazaka O, Chua M, et al. Metallic biomaterials: current challenges and opportunities. Materials. 2017;10(8):884. doi:10.3390/ ma10080884

32. Ray S, Thormann U, Eichelroth M, et al. Strontium and bisphosphonate coated iron foam scaffolds for osteoporotic fracture defect healing. Biomaterials. 2018;157(1):1-16. doi:10.1016/j.biomaterials.2017.11.049

33. Sila-Asna M, Bunyaratvej A, Maeda S, et al. Osteoblast differentiation and bone formation gene expression in strontium-inducing bone marrow mesenchymal stem cell. Kobe J Med Sci. 2007;53(1-2):25-35.

34. Guilak F, Cohen DM, Estes BT, et al. Control of stem cell fate by physical interactions with the extracellular matrix. Cell Stem Cell. 2009;5 (1):17-26. doi:10.1016/j.stem.2009.06.016

35. Lutolf MP, Blau HM. Artificial stem cell niches. Adv Mater. 2009;21(32-33):3255-3268. doi:10.1002/adma.200802582

36. Fisher OZ, Khademhosseini A, Langer R, et al. Bioinspired materials for controlling stem cell fate. Acc Chem Res. 2010;43(3):419-428. doi:10.1021/ar900226q

37. JARCHO MICHAEL. Calcium phosphate ceramics as hard tissue prosthetics. Clin Orthop Relat Res. 1981;217(157):259-278.

38. Lin K, Xia L, Gan J, et al. Tailoring the nanostructured surfaces of hydroxyapatite bioceramics to promote protein adsorption, osteoblast growth, and osteogenic differentiation. ACS Appl Mater Interfaces. 2013;5(16):8008-8017. doi:10.1021/am402089w

39. Kim H, Camata RP, Lee S, et al. Crystallographic texture in pulsed laser deposited hydroxyapatite bioceramic coatings. Acta Mater. 2007;55 (1):131-139. doi:10.1016/j.actamat.2006.08.008 


\section{Publish your work in this journal}

The International Journal of Nanomedicine is an international, peer-reviewed journal focusing on the application of nanotechnology in diagnostics, therapeutics, and drug delivery systems throughout the biomedical field. This journal is indexed on PubMed Central, MedLine, CAS, SciSearch ${ }^{\circledR}$, Current Contents ${ }^{\mathbb{B}} /$ Clinical Medicine, Journal Citation Reports/Science Edition, EMBase, Scopus and the Elsevier Bibliographic databases. The manuscript management system is completely online and includes a very quick and fair peer-review system, which is all easy to use. Visit http:// www.dovepress.com/testimonials.php to read real quotes from published authors.

Submit your manuscript here: https://www.dovepress.com/international-journal-of-nanomedicine-journal 